\title{
An Empirical Analysis on Enterprise Microblog
}

\author{
Nan ZHANG ${ }^{1,2, a}$, Yue-Ting CHAI ${ }^{1, b}$, Hong-Bo SUN ${ }^{1,3, c}$ \\ ${ }^{1}$ National Engineering Laboratory for E-Commerce Technology, Tsinghua University, Beijing \\ 100084, China \\ ${ }^{2}$ Changping Noncommissioned Officer School, Academy of Equipment, Beijing 102249, China \\ ${ }^{3}$ DNSLAB, China Internet Network Information Center, Beijing 100190, China \\ azhangn05@gmail.com, bchaiyt@mail.tsinghua.edu.cn, 'sunhongbo02@tsinghua.org.cn
}

Keywords: microblog, E-commerce, information spread, forward.

\begin{abstract}
As a promising social medium, Sina microblog has been adopted to enlarge their social networks and to prompt their products by more and more enterprises. This paper gives an empirical analysis about information spread of enterprises microblog, discovers the reason why users forward information, describes the spread law of goods information, and proposes some proved advices to improve the efficiency of microblog-based marketing.
\end{abstract}

\section{Introduction}

As one of the most famous communication media in China that has nearly 5 billion users, Sina microblog (www.weibo.com) is very popular among public figures, media, official departments, and enterprises. People use it to acquire information, to enlarge and maintain social network, and to have funs. They enjoy themselves on following option leaders and sharing information with their fans or friends, which makes information spread rapidly and widely in a new manner.

Nowadays, many enterprises promote marketing on microblog and other new media. Web 2.0 has provided a technological environment to promote interaction between business and customers. Because of high spread speed, more and more enterprises prefer to publish product information on the microblog platform rather than offline or other advertisement platforms.

Schöndienst,V.et al.[1] proposed that enterprise should take microblog as a tool for brand building, communication, and knowledge management. Hennig-Thurau et al. [2] think that twitter improves real-time information exchange with customers and master their behavior anytime and anywhere. SocialBeta and Sina Corporation[3] have published a report on the time or frequency of enterprise microblog together, they used more than 120 samples to figure out the most active time of users, the forward rate and the comment rate.

The purpose of this paper is to reveal the spread law of the goods information on microblog, and propose a model to describe the fans behavior about the goods information to help enterprises to operate their microblogs and convert more users to customers.

\section{The Characteristics of Enterprise Microblog}

\section{About Information Spread on Microblog}

The microblog users could follow other users, forward messages and comment messages, following others forms a complex network, which is the basic of the spreading, and then forwarding messages makes information spread widely. People could gain information from its followers continually, if they forward it, their fans will also gain the messages, and so on.

The high speed for Sina microblog's information spread is owed to its structure first. Sina microblog has both small world characteristics and power-law characteristics [4], where lots of public figures gather here, we call them leader users. Leader users have a key effect in information flowing. The 
important feature of leader users is that they have a large number of fans. In fact, Sina microblog is more likely a community structure.

\section{The Advantage of New Media Marketing}

Enterprises use microblog to process the marketing, in traditional, enterprises mainly have three channels to advertise their commodities: (1) advertising on web portals or vertical websites online or public places offline; (2) bidding rank with Google.com or Baidu.com etc.; (3) occupying a conspicuous location on the e-commerce platform. Though, these methods could get a certain effect to raise the influence of the enterprises' goods, but its efficiency is still a little lower and always cost a lot, because the Ads receivers may be not fit with the goods, and the enterprises never know where their or potential customers are.

But on microblog, people follow what they are interested in, and gain the messages continually, and also, enterprises could see their fans and have the knowledge of the market. Enterprises microblog attracts lots of fans and send goods or other information every day to maintain the fans, sometimes they provide sales promotion to encourage the fans forward the goods information, especially the new arrival, and to transmit the information to an extensiveness users.

So we think that, the enterprises operate the microblog accounts, benefits from: (1) lower cost, less staffs could manage the account's content about the new goods information; (2) high efficiency, the people receive the goods information are all interested in them, the customers will never complain with the redundancy messages, or they could cancel "follow"; (3) customer management, they could read the customers information to apply to the marketing or producing.

\section{The Structure of Enterprise Microblog}

Different enterprises have different account system on microblog. We classify them to two classes: e-commerce platform, such as jd.com, dangdang.com; brand style, such as Xiaomi, Sumsang(two famous mobile brand). These accounts have operated their own fans independently, each account has gather amounts of fans and a special manager. Take jd.com as an example, they have channels covering computer, automobile, Maternity \& Baby, appliance, etc., and the CEO Liu Qiangdong also have a close relationship with these accounts, each account have several millions of fans, achieve a total 37.35 million person-time.

Table 1, The accounts of Jd.com on Sina microblog

\begin{tabular}{|c|c|c|c|c|c|}
\hline ID & User name & Fans & Follows & Messages & Create date \\
\hline 1 & JD Foods & 1278006 & 27 & 212 & $2012 / 9 / 4$ \\
\hline 2 & JD EBOOK & 1047445 & 1851 & 4955 & $2012 / 5 / 14$ \\
\hline 3 & JD Automobile & 3479949 & 62 & 392 & $2012 / 8 / 16$ \\
\hline 4 & JD Clothing & 206327 & 245 & 4223 & $2011 / 10 / 22$ \\
\hline 5 & JD Maternity \& Baby & 3835114 & 454 & 1242 & $2011 / 12 / 3$ \\
\hline 6 & JD Appliances & 3987207 & 245 & 1374 & $2011 / 6 / 8$ \\
\hline 7 & JD General merchandise & 5158637 & 183 & 5997 & $2011 / 4 / 11$ \\
\hline 8 & JD Audio & 1181984 & 140 & 7751 & $2011 / 8 / 10$ \\
\hline 9 & JD Mobile & 6701502 & 203 & 5668 & $2011 / 4 / 22$ \\
\hline 10 & JD PC digital & 6467388 & 48 & 2126 & $2011 / 11 / 28$ \\
\hline \multirow[t]{2}{*}{11} & JD Mall & 4006661 & 118 & 11158 & $2010 / 3 / 24$ \\
\hline & Total & 37350220 & 3576 & 45098 & \\
\hline
\end{tabular}

Why Jd.com has so many accounts? People's demands are quite different and their demands are specific and corresponding with single commodity. In another hand, the user who is interested with mobile may not be interested with e-books. Thus, in fact, Jd.com has classified their customers according to their demands such as they do on the portal website. Many other enterprises such as Xiaomi, Dangdang.com also have similar accounts system, but also lots of them are not standard and short of uniform management. 
Another advantage is that, when one account send a message, other accounts could help forward and gain more forwards and more fans.

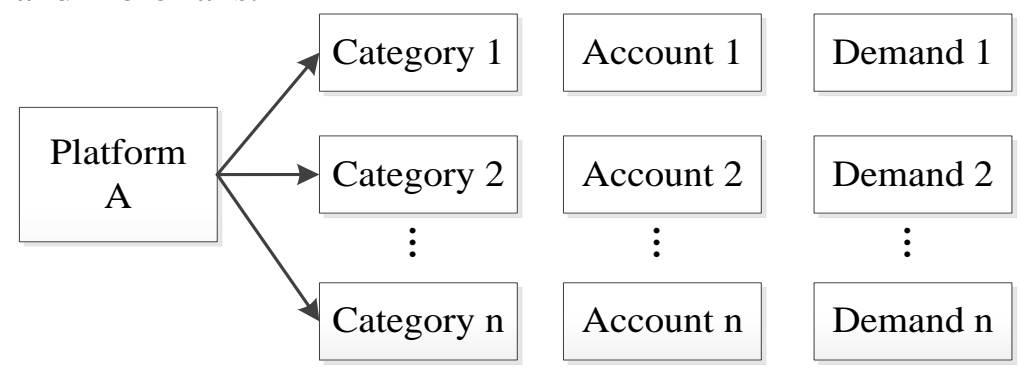

Fig.1 E-commerce platform always create several account according to goods categories

\section{The Spread of Goods Information on Microblog}

\section{The Reason that User Forward Information.}

There are lots of reasons that users forward information. Danah[5] listed 10 reasons that user forward message on microblog, include delivering new information to others, adding new comments, agreeing with others openly etc.. Song et al. [6] have proposed a model to describe user behavior on microblog, and the most important feature is user's interest to the message or the sender.

To enterprise microblog's fans, they forward information mostly because of they could benefit from the behavior, sometimes they also convey their favorite or good wishes, somebody may show off the psychological.

\section{The Characteristics of Information Spreading}

A visual index to evaluate the management level of the accounts is the rate of forward and comment, which means the level of the fans prefer to join into the message's propagation. The forward and comment rate could be defined as:

$$
r=(\bar{f}+\bar{c}) / n
$$

While, $r$ indicates forward and comment rate of an account, $\bar{f}$ and $\bar{c}$ indicate recent average number of forward and comment separately, here we take 50 samples with each account, and $n$ indicates the number of the account's fans.

As that show in Fig.2, Maternity \& Baby, automobile, and PC digital are the top three which have a high engagement.

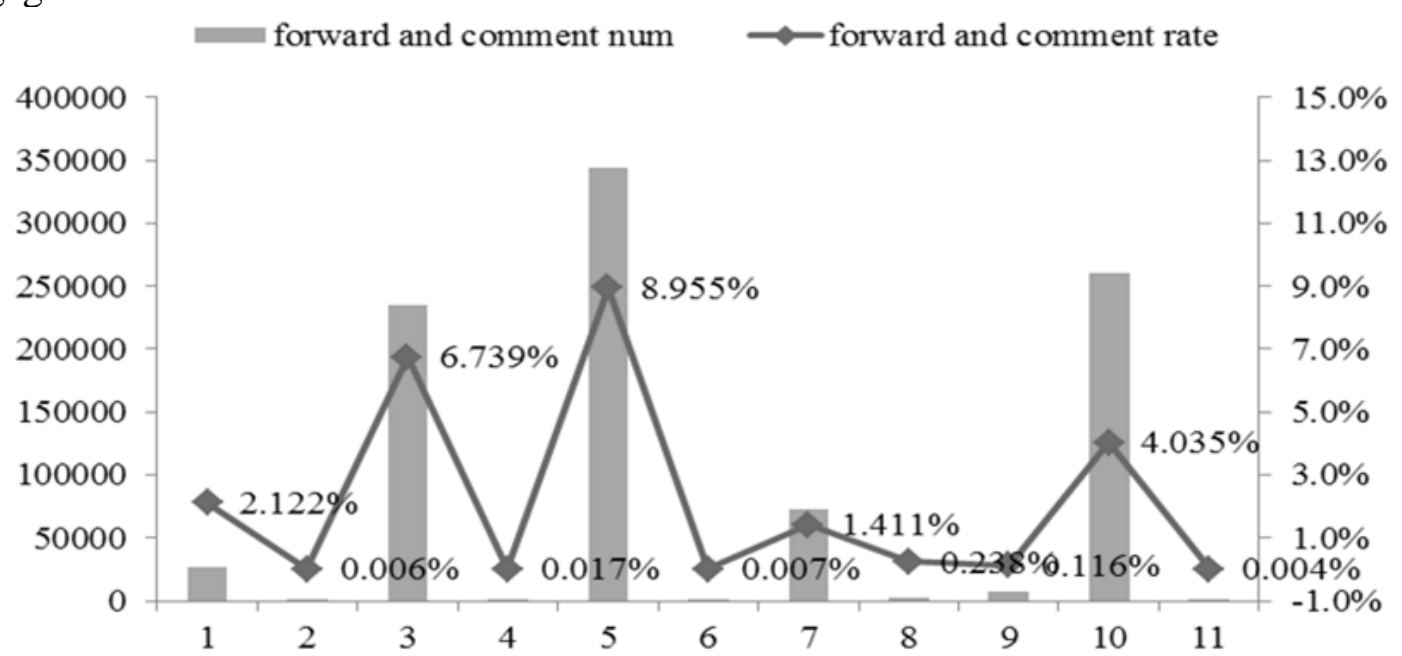

Fig. 2 Forward and comment rate and average number of Jd.com's different accounts 
Another index is the variance of the recent times of forward and comment. We can see that Maternity \& Baby, automobile, and PC digital are still the top three. So we can conclude that users' high engagement have three main reasons: (1)users prefer the free goods, so if the massage doesn't contain the opportunity to gain the awards, they do not forward; (2)women have a high activity, Jd.com is famous for digital things, Maternity \& Baby's users are most mothers, they will try to find time to hunt cheap things and are high on show themselves; (3)the higher level of the incentives, the more attention there is, automobile always gives a big promotions, and users have opportunity to gain it only with forwarding the message.

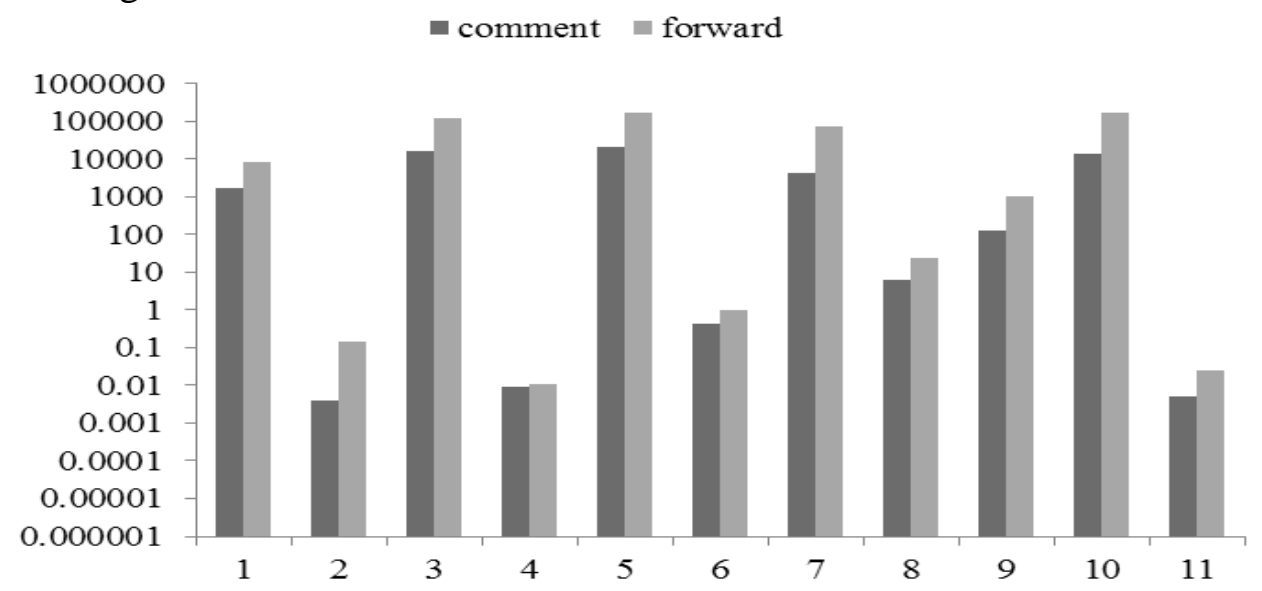

Fig.3 Forward and comment variance of Jd.com's different accounts

\section{Describe a message's propagation path}

Here, we will crawl a message send by JD Mobile channel, which has 449 forwarding times until stabilizing. The message (http://weibo.com/2100925373/AnSym59xq) is about TCL mobile, a famous brand of mobile, which also have lots of fans on Sina microblog. The message provides 5 awards, and the user will have opportunity if they forward the message.

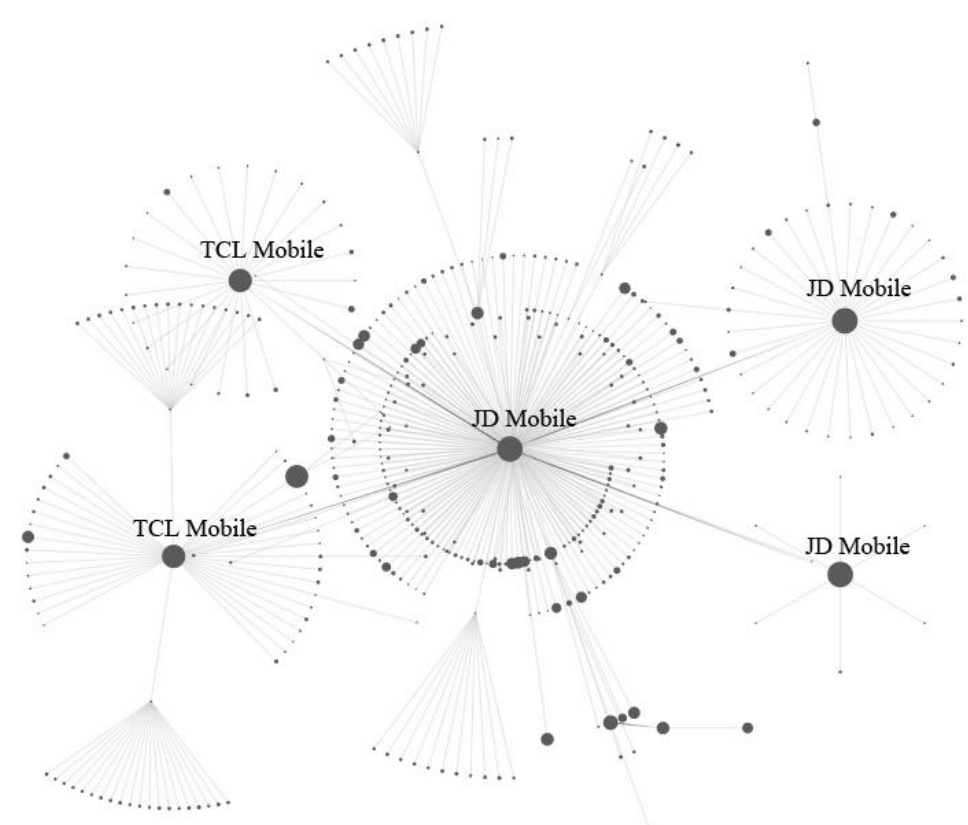

Fig.4 The message's spread tree, which send by Jd.com mentioned TCL mobile

We use a visual tool [7] to draw the propagation path of the message. The spread tree is "JD mobile"-centric, in the process, the message is also forward by itself and "TCL mobile", direct of the 
widely spread. Furthermore, 40 percentages of the forwards are the JD mobile's fans directly, while 45 percentages of the forwards are TCL mobile's fans and JD mobile's second forward.

As that show in Fig.5, Fig.6 and Fig.7, when JD mobile send the message, its big number of fans present a thick forwards at the first step; after the message has been sent 42-45 hours, JD mobile and TCL mobile repost the message, we can see the second step; after 116 hours, JD mobile repost the message for the third time, and the third step appears. Then, the repost density almost has no change. At last, there are nearly 25 million person-times and 9.8 million persons (except for the user who read the message more than once) may have read the message,

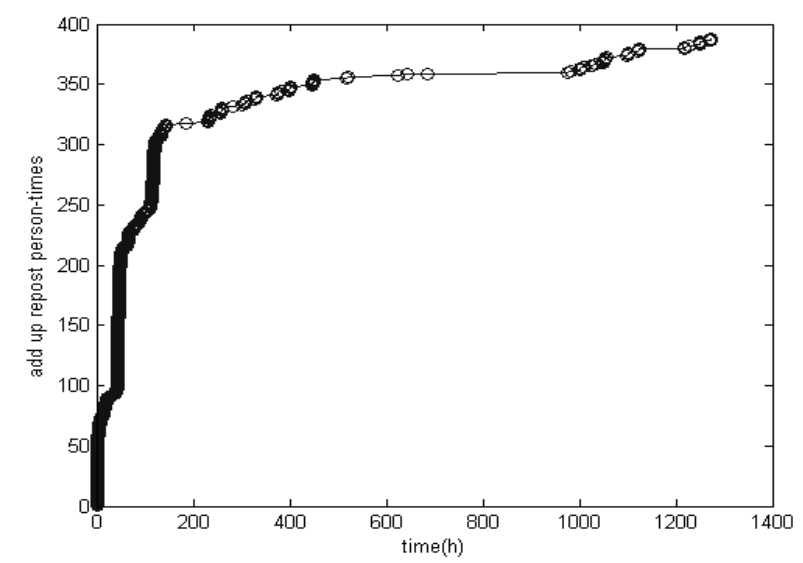

Fig.5 Add up person times on the person who receives the message

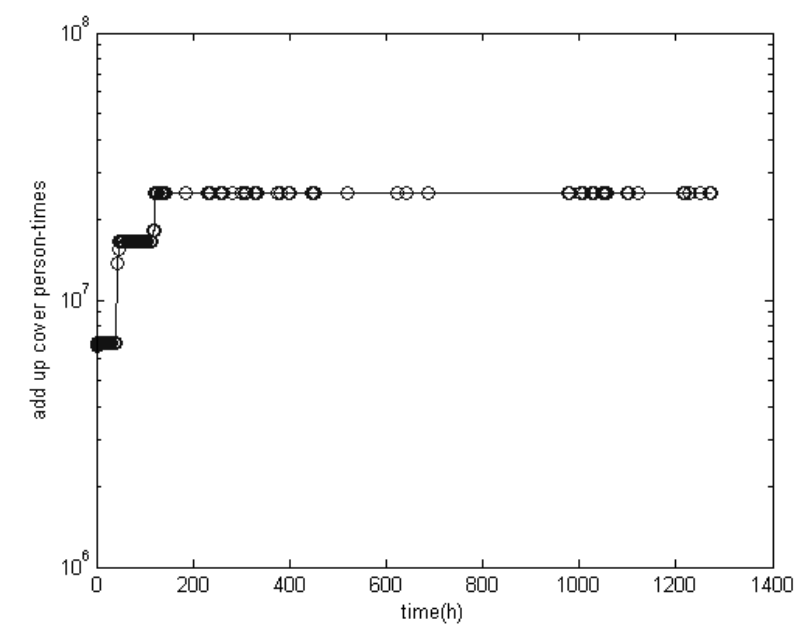

Fig.6 Add up person times on forwarding the message

So we could find there are three pulses in the newly increased repost person-times graph. We suppose that, in the goods information propagation process, people value the level of their profit, the enterprise microblog' predominant task is trying to spread the message to more users, so it needs to find more partners. 


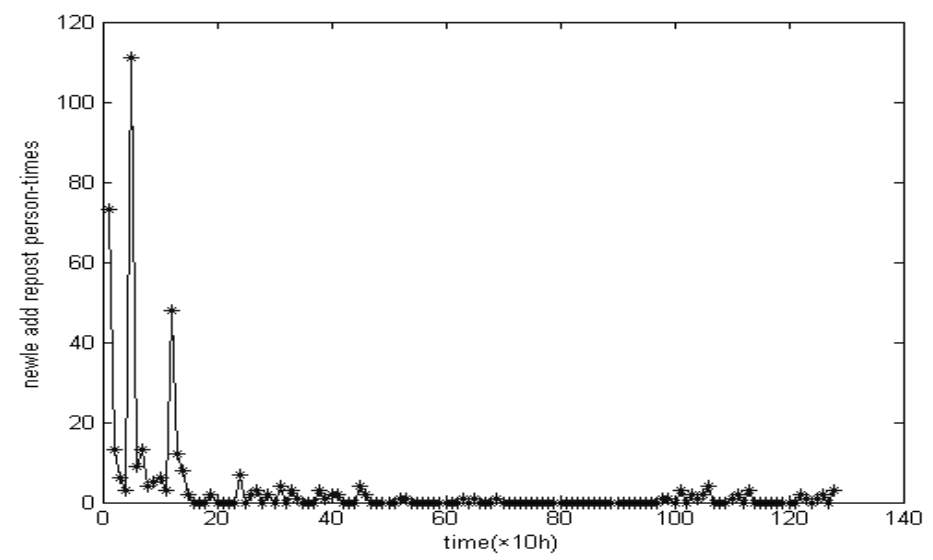

Fig.7 Newly increased forward person-times in the message propagation process

\section{Advice on enterprise microblog}

According to above, enterprise should normalize their goods information publish channels on microblog focus on below aspects:

(1) Create several accounts according to commodity classification, to meet customer's specific demand;

(2) Connect with more other related leader users each other, such as other famous brand, and the accounts belong to the same company, so that they can share information and fans, react rapidly; in addition, mention other direct stakeholder leaders is greatly helpful;

(3) Provide sales promotion in a suitable frequency, we can see that a successful information spread could last 100-400 hours, so we advise the enterprise give a price-off or prize 2-4 weeks a time. As for the cost of the marketing, enterprise could do according to its abilities.

(4) About the content, add a picture to the message, and focus on the new arrival commodities. Also, they can send some common interesting things to attract more fans and improve closeness with the customers, at this aspect, Xiaomi is a successful model.

\section{Conclusions and future work}

In the paper, an empirical analysis on enterprise microblog has been carried out with Sina microblog data.

First, we discuss the importance of the new media in enterprise marketing. As a convenient information access tool, microblog has characteristics of small world and power law, so that it can improve information matching efficiency and speed.

Then, user behaviors on microblog are also studied in this paper, and the structure of enterprise account system is introduced to analyze user behaviors.

An example about a message on TCL mobile has been inspected. Its propagation path is used to illustrate the uncovered law of information spread.

At last, some advices are listed on how to manage an enterprise microblog.

In future work, we try to copy microblog principle to e-commerce websites, everybody will have its own page with interested information, replace of traditional information that pushed to customers.

\section{Acknowledgement}

This research was partly financial supported by NELECT and DNSLAB.

\section{References}

[1] Schöndienst, V., et al., Micro-Blogging Adoption in the Enterprise: An Empirical Analysis. Wirtschaftsinformatik, 2011. 22. 
[2] Hennig-Thurau T, Malthouse E C, Friege C, et al. The impact of new media on customer relationships[J]. Journal of Service Research, 2010, 13(3): 311-330.

[3] Information on http://www.socialbeta.com

[4] Wang, R., Y. Jin and F. Li. A Review of Microblogging Marketing Based on the Complex Network Theory. 2012: Springer.

[5] Java, A., et al., Why we twitter: An analysis of a microblogging community. Advances in Web Mining and Web Usage Analysis, 2009: p. 118-138.

[6] Song, G., Z. Li and H. Tu, Forward or ignore: User behavior analysis and prediction on microblogging. 2012, Springer. p. 231-241.

[7] Ren, Donghao and Zhang, Xin and Wang, Zhenhuang and Li, Jing and Yuan, Xiaoru. WeiboEvents: A Crowd Sourcing Weibo Visual Analytic System, IEEE Pacific Visualization Symposium (Pacific Vis 2014), Visualization Notes, Yokohama, Japan, 2014. 